\title{
Oxygen changes drive non-uniform scaling in Drosophila
}

\section{melanogaster embryogenesis [version 1; peer review: 2}

\section{approved, 1 approved with reservations]}

\author{
Steven G. Kuntz'1,2, Michael B. Eisen ${ }^{1-3}$ \\ ${ }^{1}$ Department of Molecular and Cell Biology, University of California, Berkeley, Berkeley, CA, USA \\ ${ }^{2}$ Howard Hughes Medical Institute, University of California, Berkeley, Berkeley, CA, USA \\ ${ }^{3}$ Department of Integrative Biology, University of California, Berkeley, CA, USA
}

\section{V1 First published: 23 Oct 2015, 4:1102 \\ https://doi.org/10.12688/f1000research.7221.1}

Latest published: 23 Oct 2015, 4:1102

https://doi.org/10.12688/f1000research.7221.1

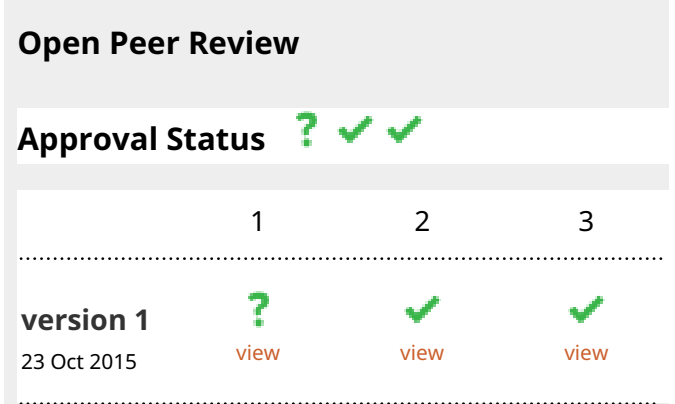

1. Sofia Lavista Llanos, Max Planck Institute for Chemical Ecology, Jena, Germany

2. Angela H. DePace, Harvard Medical School, Boston, USA

3. Pablo Wappner, Leloir Institute Foundation, Buenos Aires, Argentina Any reports and responses or comments on the article can be found at the end of the article. 
Corresponding author: Steven G. Kuntz (sgkuntz@berkeley.edu)

Competing interests: MBE is on the International Advisory Board for F1000.

Grant information: This work was supported by a Howard Hughes Medical Institute investigator award to MBE and by NIH grant HG002779 to MBE. SGK was supported by the National Institutes of Health under Ruth L. Kirschstein National Research Service Award (F32-FGM101960A) from the National Institute of General Medical Sciences.

The funders had no role in study design, data collection and analysis, decision to publish, or preparation of the manuscript.

Copyright: @ 2015 Kuntz SG and Eisen MB. This is an open access article distributed under the terms of the Creative Commons

Attribution License, which permits unrestricted use, distribution, and reproduction in any medium, provided the original work is properly cited.

How to cite this article: Kuntz SG and Eisen MB. Oxygen changes drive non-uniform scaling in Drosophila melanogaster embryogenesis [version 1; peer review: 2 approved, 1 approved with reservations] F1000Research 2015, 4:1102

https://doi.org/10.12688/f1000research.7221.1

First published: 23 Oct 2015, 4:1102 https://doi.org/10.12688/f1000research.7221.1 


\section{Introduction}

After discovering that the time elapsed during different morphological stages of Drosophila embryogenesis scale uniformly as temperature changes the overall time of embryogenesis ${ }^{1}$, several colleagues questioned whether the result was surprising, suggesting instead that it was a natural and trivial consequence of physical and chemical laws. To explore this possibility, and to provide orthogonal insight into the mechanisms of the control of developmental timing, we sought to manipulate developmental rate in a temperature-independent manner.

It has long been known that oxygen levels affect the rate of animal development ${ }^{2}$. In D. melanogaster mild hypoxia (10\% oxygen) slows time to eclosion relative to normoxia ( $21 \%$ oxygen), while hyperoxia ( $41 \%$ oxygen) accelerates time to eclosion in a temperature-dependent manner. This suggested to us that studying the effects of varying oxygen levels on embryogenesis might provide an ideal complement to our earlier studies of the effects of temperature.

Although the scaling behavior of embryos grown at different oxygen concentrations has not been previously characterized, there have been extensive studies of the effect of oxygen on the D. melanogaster embryo. In normal development, oxygen sensation plays a crucial role in cellular differentiation, organogenesis, and growth rate. It is known to influence Notch, Wnt, and OCT4 pathways $^{3}$ and at low levels slows growth by driving components of the Tor pathway ${ }^{4,5}$. It is critical for hematopoiesis ${ }^{6}$, myogenesis ${ }^{7,8}$, and notochord and liver formation in vertebrates ${ }^{9,10}$.

Hypoxic Drosophila syncytial embryos arrest at a metaphase checkpoint $^{11}$ and resume development under normoxia if the hypoxic period is not too $\operatorname{long}^{12}$. Cellularized embryos survive longer hypoxic periods, up to several days ${ }^{13}$. However, hypoxic arrest is not entirely benign, as even brief periods of hypoxia lead to smaller bodies and wings, driven in part by decreased cell size $\mathrm{s}^{14-16}$. Active oxygen sensing and nitric oxide signaling drive this arrest, which is independent of the electron transport chain ${ }^{13,17,18}$. Hypoxia tolerance also varies between tissues ${ }^{19}$ and possibly between stages of embryonic development. Hyperoxia, on the other hand, is toxic ${ }^{20,21}$ and drives malformation of mitochondria ${ }^{22}$.

The response of the D. melanogaster embryo to oxygen is highly conserved, in both function and molecular mechanism ${ }^{21,23-25}$. Drosophila, like other animals, regulate metabolism and gene expression in response to changes in oxygen levels through the $H I F-1 \alpha$ pathway, which communicates with the Tor and VEGF pathways. Under normal conditions, proline residues of simalar (sima/hif-1/HIF-1 $\alpha$ ) are hydroxylated by prolyl hydroxylase $(\mathrm{Hph} /$ egl-9/EGLN) to both inactivate sima/hif-1/HIF-1 $\alpha$ and target it for Vhl-dependent degradation ${ }^{19,26}$. The prolyl hydroxylase Hph/egl-9 is itself negatively regulated under hypoxia by the cystathionine $\beta$-synthase $C b s / c y s l-1 / C B S$, an ambient oxygen sensor via hydrogen sulfide signaling. sima has an oxygen-dependent degradation domain with a nuclear export sequence ${ }^{27}$. Thus, only during hypoxia does sima escape degradation and accumulate in the nucleus ${ }^{26}$. Rather than serving as a switch, the process is dynamic, with greater levels of oxygen accelerating both the degradation and nuclear export of $\operatorname{sima}^{27}$.

Over the course of development, changes in insulin levels, the metabolic state of the embryo, and temperature may impact the oxygen response $^{24,28-31}$, either directly or through its dependence on transcription, nuclear-import and export, prolyl hydroxylation and Vhldependent degradation ${ }^{32}$.

Here we use time-lapse imaging of embryos under a range of oxygen concentrations with precise temperature control to monitor the effects on developmental timing and morphology. In covering hypoxic through hyperoxic and warm through cold conditions, we have collected dynamic data on how the developing embryo responds to oxygen, and how that response is affected by temperature.

\section{Methods}

Rearing and imaging of Drosophila

Drosophila melanogaster, OreR, were reared and maintained on standard fly media at $25^{\circ} \mathrm{C}$. Egg-lays were performed in medium cages on $10 \mathrm{~cm}$ molasses plates for 1.5 hours at the temperature at which the lines were maintained after pre-clearing. Embryos were collected and dechorionated with fresh $50 \%$ bleach solution (3\% hypochlorite final) for 60 seconds in preparation for imaging.

Embryos were monitored by modifying a temperature control system $^{1}$ in which an aluminum bar was embedded in an acrylic box (TAP Plastics). Both ends of the aluminum bar were external to the box and bound to Peltier heat pumps and heat sinks. A thermistor connected to the aluminum bar provided feedback to maintain the temperature using an H-bridge temperature controller (McShane Inc., 5R7-570). Embryos were glued ${ }^{33}$ to oxygenpermeable film (lumox, Greiner Bio-one), covered with Halocarbon 700 oil (Sigma), and placed over holes drilled in the aluminum for imaging. An oxygen sensor (Grove Gas sensor (O2)) was placed in the box and connected to an external computer (Arduino-style Seeeduino V3.0 (Atmega 328P)). Finally, the box was sealed with two gas inputs and an over-pressure release. The computer utilized the oxygen sensor input and controlled two valves via NPN transistors, one connected to an oxygen tank and regulator and one connected to a nitrogen tank and regulator, to maintain specific oxygen concentrations in the box (Figure 1A).

Time-lapse imaging with bright field transmitted light was performed on a Leica M205 FA dissecting microscope with a Leica DFC310 FX camera using the Leica Advanced Imaging Software (LAS AF6000 version 2.3.5) platform. Greyscale images were saved from pre-cellularization to hatch. Z-stacked images were saved every two minutes (five minutes at $17.5^{\circ} \mathrm{C}$ ). Analysis data available from http://dx.doi.org/10.6084/m9.figshare.1572474 and imaging data available from http://dx.doi.org/10.6084/m9.figshare.1582639. 
A

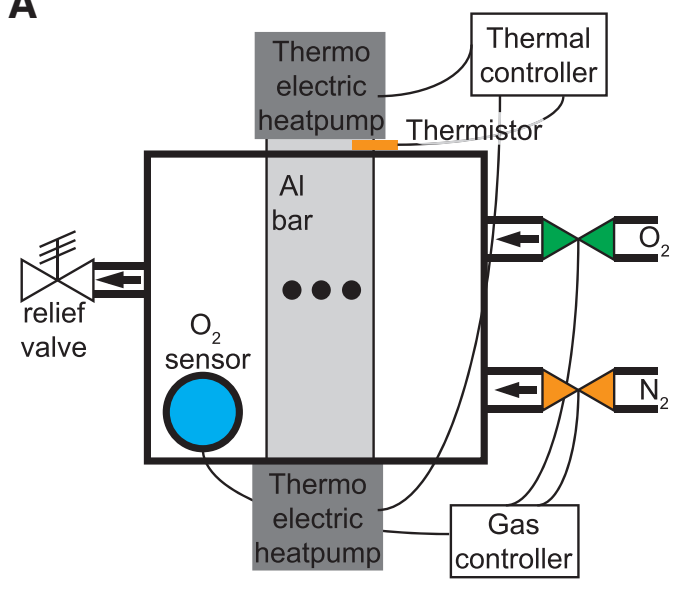

B

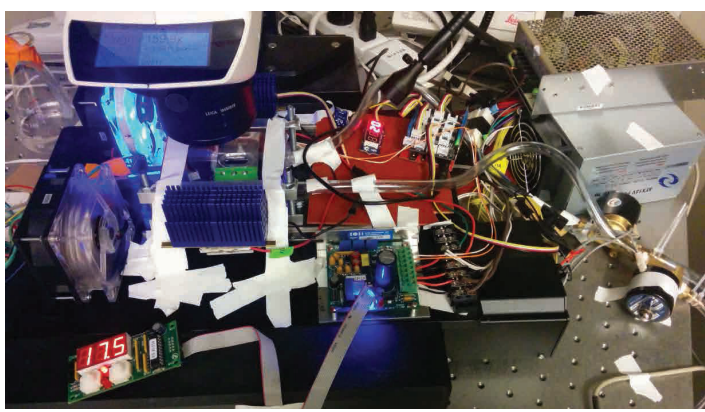

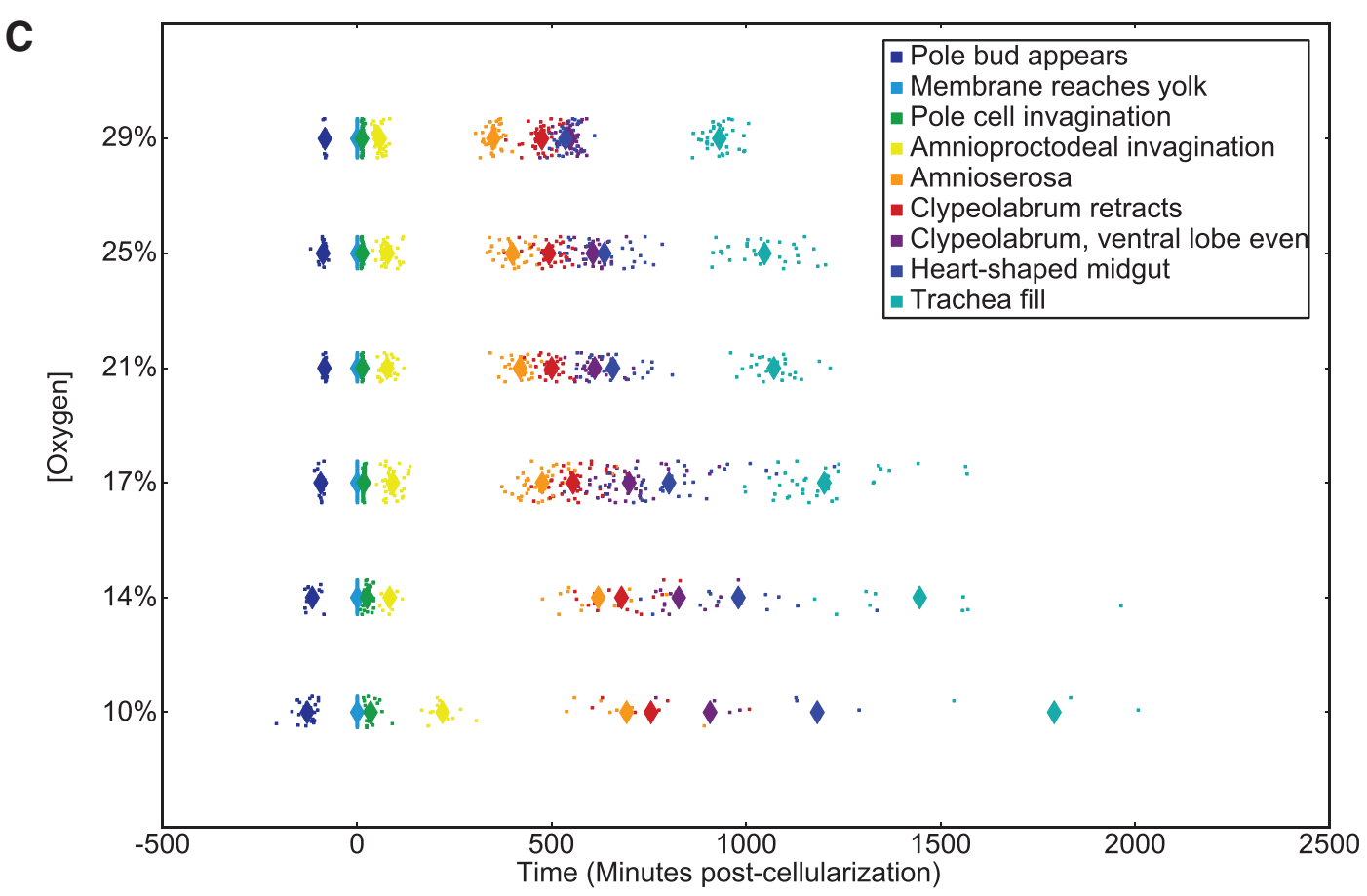

Figure 1. Developmental rate responds to oxygen concentrations. (A) The oxygen control schematic. A thermistor embedded in the aluminum bar provides temperature data to the temperature controller, which in turn adjusts the voltage to the thermo-electric controllers (Peltier). An oxygen sensor in the airtight box provides feedback on oxygen concentrations to the gas controller, which opens and closes oxygen and nitrogen valves accordingly. Embryos are imaged in the center of the aluminum bar within the airtight box, indicated by the black dots in the schematic. (B) Image of the oxygen control setup mounted on the microscope at $20 \%$ oxygen and $17.5^{\circ} \mathrm{C}$. (C) Developmental rate across all stages changes with the oxygen concentration, performed at $27.5^{\circ} \mathrm{C}$. Each animal is represented with a dot, with averages represented with a large diamond. Developmental times here are zeroed on the end of cellularization. 
Z-stack and image analysis were conducted as previously described ${ }^{1}$. Events selected for measurement (pole-bud appearance, membrane reaching yolk, pole cell invagination, amnioproctodeal invagination, amnioserosa exposure, clypeolabrum retraction, clypeolabrum and ventral lobes being even, heart-shaped midgut, and the filling of the trachea) were identified by hand using a graphical user interface. Oxygen dependent trends were analyzed with least-squares regression. Significant differences between events in their response to oxygen changes were determined by comparing the pooled estimate of the variation about the regression line using a t-test with a Bonferonni multiple testing correction. For modeling total developmental response to oxygen and temperature changes, leastsquares regression was used based on linear, exponential, logarithmic, polynomial (up to cubic), and inverse proportional models, with the models consistently yielding the best Pearson productmoment correlation coefficient being selected. For the combined effect of both oxygen and temperature, all possible combinations of exponential and inverse-proportional models identified for each component were attempted with least squares surface regression. The curve fit with the best adjust correlation coefficient $\left(\bar{R}^{2}\right)$ across all available data was selected. All scripts are available at github. com/sgkuntz/OxygenCode.

\section{Results}

\section{Oxygen concentration controls developmental rate}

We used automated time-lapse imaging in an airtight box with oxygen concentration control $( \pm 1 \%)$ and precise temperature control $\left( \pm 0.1^{\circ} \mathrm{C}\right)$ to track development using previously described methods ${ }^{1}$. We investigated embryos raised at constant oxygen concentrations $\left(29 \%, 25 \%, 21 \%, 17 \%, 14 \%\right.$, and $\left.10 \% \mathrm{O}_{2}\right)$ and kept at three different temperatures $\left(17.5^{\circ} \mathrm{C}, 22.5^{\circ} \mathrm{C}\right.$, and $\left.27.5^{\circ} \mathrm{C}\right)$, giving a total of eighteen specific conditions with over 800 embryos. A schematic of the setup is provided in Figure 1A. The actual setup is shown in Figure 1B.

In agreement with previous research, developmental rate correlates with oxygen concentrations (Figure 1C). Hyperoxia accelerates development, allowing embryos to hatch sooner than they would under normal atmospheric conditions. Hypoxia slows development in a dose-dependent fashion. As oxygen levels fall, an increasing fraction of embryos die or arrest their development. Therefore, there are fewer embryos shown in Figure 1C at lower oxygen concentrations due to low rates of successful development, despite similar numbers of animals being prepared for imaging (Table S1).

\section{Oxygen-dependent developmental scaling is non-uniform and temperature-dependent}

By tracking and analyzing nine morphological stages as oxygen concentrations change, we identified significant differences in scaling between major morphological events. While all morphological events speed up with increasing oxygen concentrations (Figure 1C), their changes in speed are notably different. Syncytial development, as measured by the time between the appearance of the pole bud and the end of cellularization, takes proportionally less time as oxygen concentrations decrease, indicating that this stage is not slowed as much by decreasing oxygen (Figure 2A). The stages of gastrulation (end of cellularization, pole cell invagination, and amnioproctodeal invagination) are relatively uniformly affected. Germ band retraction, as measured by amnioserosa exposure, tracks subtly but inversely with syncytial development. More striking are the oxygen-dependent changes observed in head involution (clypeolabral retraction and advancing of the ventral lobe to match the clypeolabrum) and gut formation (heart-shaped midgut). While head involution takes proportionally more time as oxygen levels increase-meaning it does not slow as much as overall development in hypoxia-gut formation does the opposite. The midgut takes proportionally less time to form as oxygen levels increase, meaning it responds more strongly to increases in oxygen than overall development. This juxtaposition of behaviors leads to an inversion of when the cephalic lobes are even versus heart-shaped midgut formation. While hypoxia leads to head involution stages finishing first, hyperoxia results in the heart-shaped midgut forming first.

Surprisingly, the point of inversion varies with temperature (Figure 2). At $27.5^{\circ} \mathrm{C}$, the inversion takes place at $29 \%$ oxygen, while at $17.5^{\circ} \mathrm{C}$ the inversion falls around $19 \%$ oxygen. This may be due to an overall shift in the oxygen response curve of heart-shaped midgut formation to proportionally later in development as temperatures fall. Supplementary Figure S1 reveals how each stage of development at each oxygen concentration changes with temperature.

\section{Timing of death and arrest depend on both oxygen and temperature}

Oxygen levels affect the stage at which embryos arrest or die. Higher concentrations of oxygen (29\%) lead to more animals dying during early development, including death in the syncytium and a failure to properly gastrulate. This point of failure is similar to that observed at high temperatures with normal oxygen levels ${ }^{1}$. Lethality at $25 \%$ oxygen is actually lower than that at $21 \%$, which approximates atmospheric levels. Problems with development may be aggravated by the dechorionation and mounting procedure. At high temperatures $\left(32.5^{\circ} \mathrm{C}\right)$ and high oxygen $(29 \%)$, almost all embryos die very early in development (Table S1).

At lower oxygen levels there is a major shift from very early developmental arrest and death to mid-embryogenesis arrest (Figure 3). This holds true at all temperatures (especially at $10 \% \mathrm{O}_{2}$ ), but is most pronounced at $27.5^{\circ} \mathrm{C}$, where the effects are still seen at $14 \%$ $\mathrm{O}_{2}$. Frequently development halts during germ band retraction, preventing full exposure of the amnioserosa. The midgut primordia in these embryos routinely migrates haphazardly after arrest, coinciding with the embryo falling into morphological disarray. In embryos that pass these mid-embryogenesis stages, trachea formation often proves problematic. Commonly the trachea fails to form, which coincides with arrest late in midgut formation, following the heart-shaped midgut stage. These animals generally form functional muscle, with some twitching observed.

Higher, but still hypoxic, oxygen levels (14\% and 17\%) have a significant fraction of embryos that fail to hatch. While embryonic development appears to be completed, including the filling of the trachea with air, larvae struggle to break out of their vitelline membrane yet fail to escape. While seen in all conditions, this behavior is most prevalent in these mildly hypoxic conditions. 
A
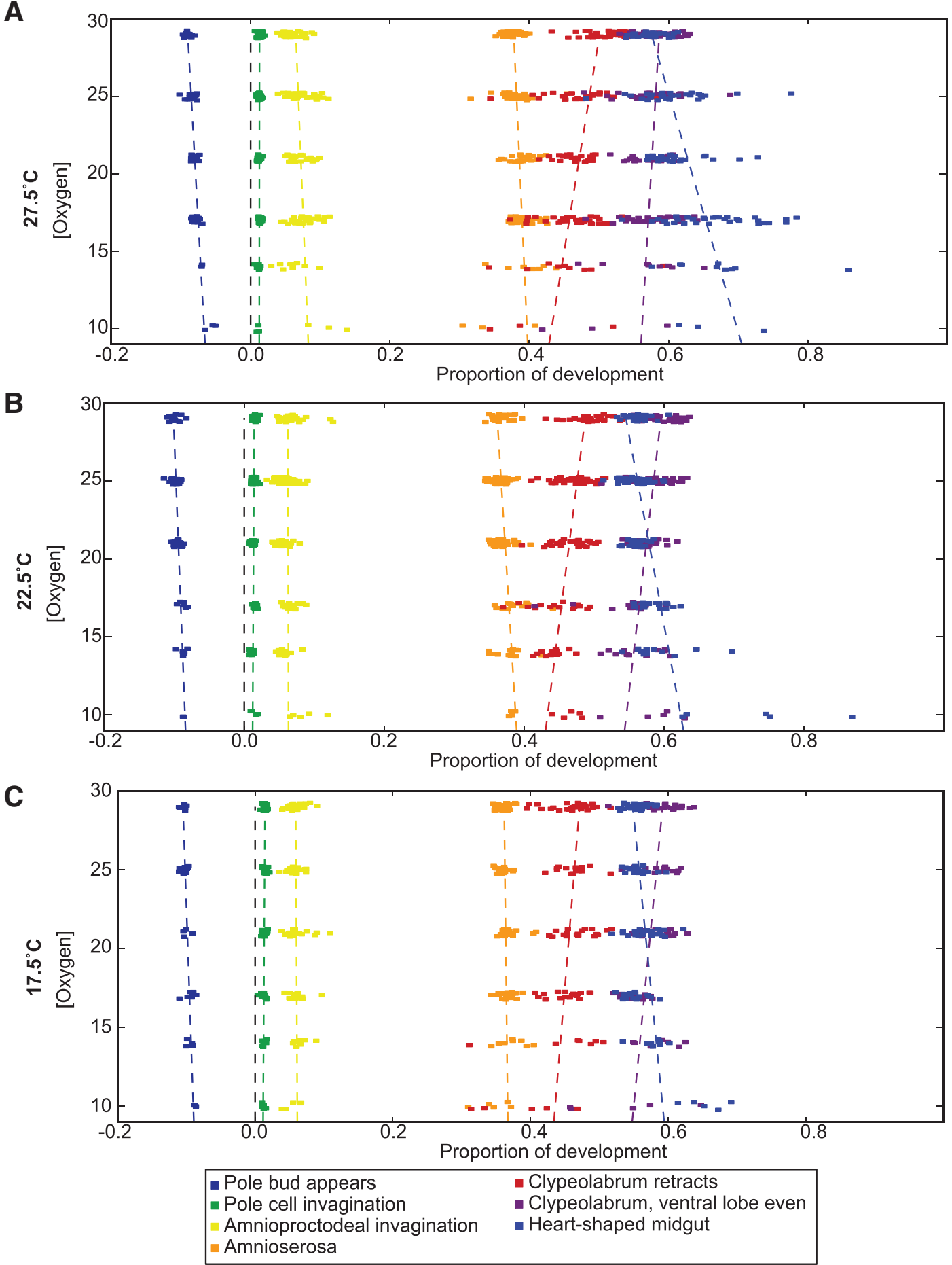

Figure 2. Oxygen-dependent changes vary with temperature. Gut formation and head involution are the most strikingly oxygen concentration dependent processes, but germ band retraction and syncytial development are also affected. Both syncytial development and head involution take proportionally more time as oxygen concentrations increase. Gut formation and germ band retraction, in contrast, take proportionally less time as oxygen concentrations are raised. These trends hold true across all temperatures, though the rates of change as a function of oxygen do vary. Development is normalized here between the end of cellularization and the filling of the trachea. 
A

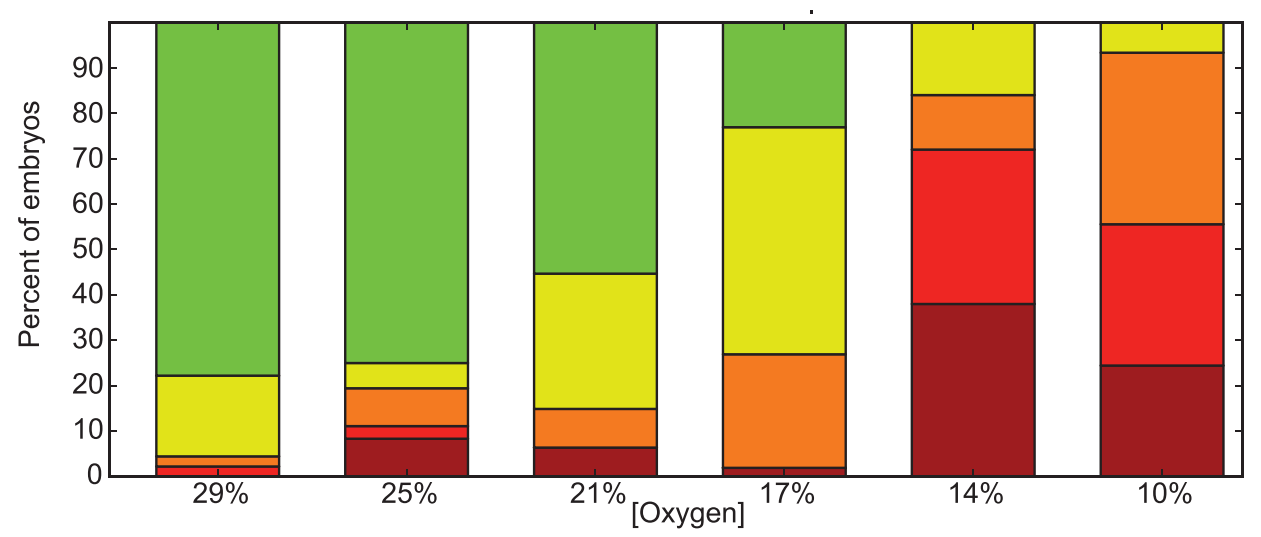

B

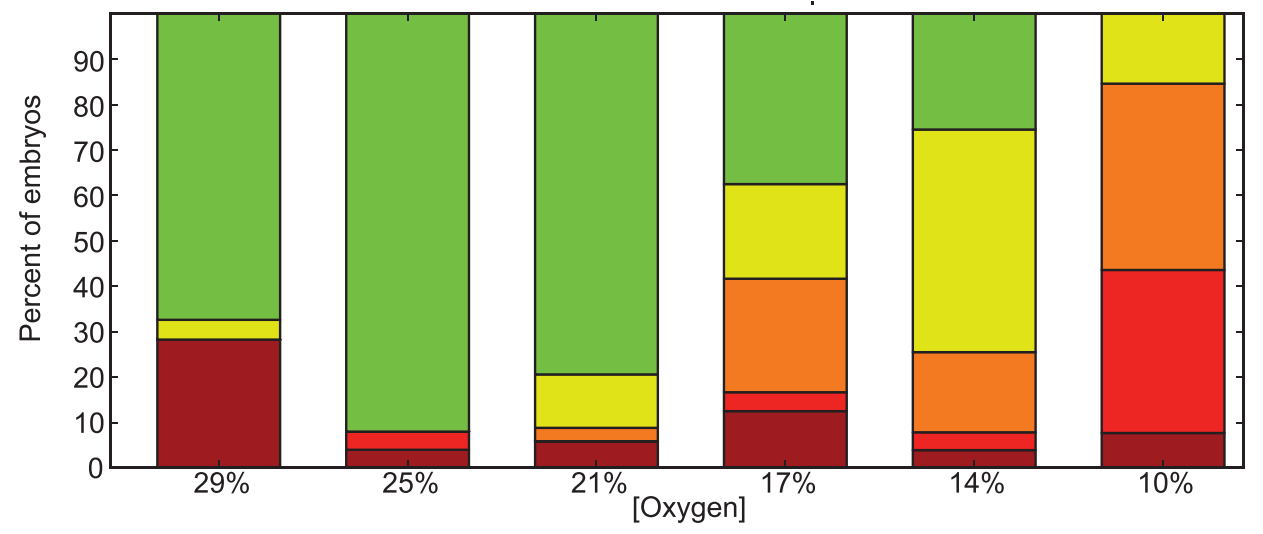

C

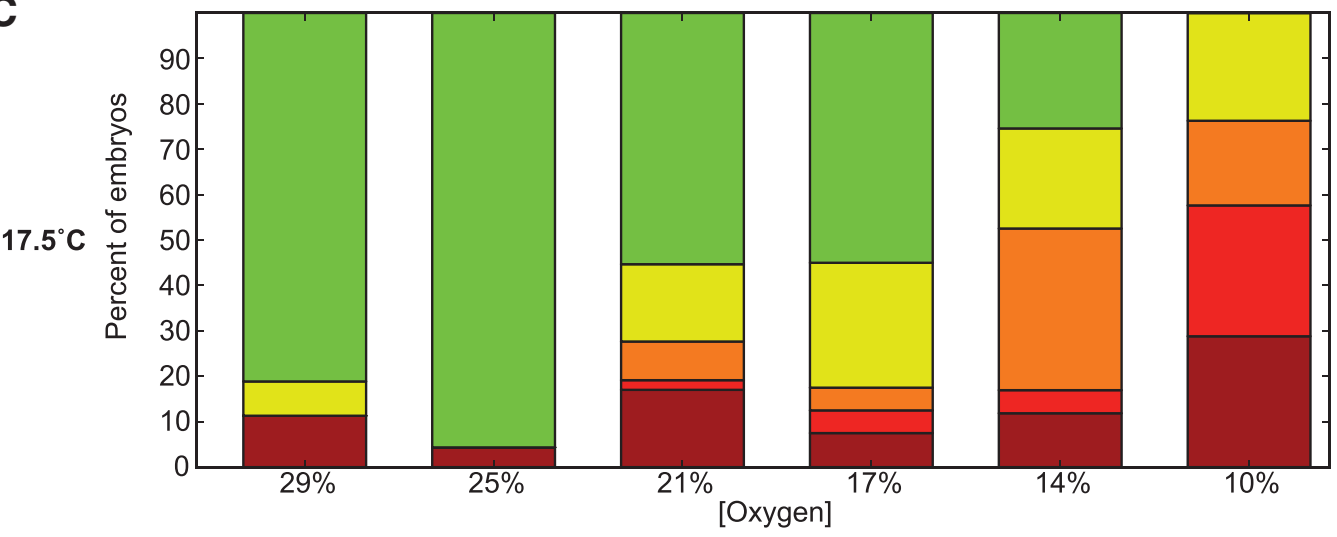

Successful hatch

Failure to hatch

Death/arrest before trachea formation

Death/arrest before heart-shaped midgut

Syncytial or gastrulation death/arrest

Figure 3. The point of failure in development depends on both oxygen and temperature. Lethality at different concentrations are shown for three different temperatures $\left(27.5^{\circ} \mathrm{C}, 22.5^{\circ} \mathrm{C}\right.$, and $\left.17.5^{\circ} \mathrm{C}\right)$. Lower concentrations of oxygen are more likely to exhibit failure during pretracheal development, with a particularly large increase in mortality between gastrulation and completion of the heart-shaped midgut (shown in red). A substantial increase in late development before trachea fill is also seen (shown in orange). Developmental arrest is frequently at germ band retraction. This is in contrast with higher oxygen concentrations, where failure is almost exclusively very early in development (shown in brick red), prior to the completion of gastrulation, or during difficulties hatching following trachea filling (shown in yellow). Highest survival is interestingly at $25 \%$ oxygen. 
Temperature influences oxygen's control of developmental rate

Decreasing oxygen concentrations from $29 \%$ to $10 \%$ at any temperature lead to an additional sixteen to eighteen hours of embryogenesis (Figure 4A). This results in a different proportional change at each temperature, with nearly a $100 \%$ increase at $27.5^{\circ} \mathrm{C}$ and only a $50 \%$ increase at $17.5^{\circ} \mathrm{C}$. This contrasts with changes in temperature, where developmental time roughly doubles over a $10^{\circ} \mathrm{C}$ range, regardless of the oxygen concentration (Supplementary Figure S2).

Changes in oxygen concentration have an inverse proportional effect on developmental rate. Least squares curve fitting was attempted with multiple models, including exponential models, for changes in oxygen concentration. The data most closely matched a model based on the Monod equation. The parameters of the response for embryogenesis as a whole change significantly with temperature, however the qualitative response is the same (Figure 4A):

$$
\begin{aligned}
& t_{17.5}=\frac{280.92}{\left[O_{2}\right]}+30.13 \\
& t_{22.5}=\frac{167.39}{\left[O_{2}\right]}+17.58 \\
& t_{27.5}=\frac{204.03}{\left[O_{2}\right]}+8.55
\end{aligned}
$$

Fitting at each oxygen concentration (Supplementary Figure S2) yields relatively good fits using an exponential Arrhenius model. These different methods of fitting can be combined and yield the best fit as a multivariable non-additive model. The overall effect of oxygen and temperature can be combined to yield (Figure 4B):

$$
t=e^{\frac{0.47\left[O_{2}\right]+31}{T}}\left(\frac{65.407}{\left[O_{2}\right]}+1.0\right)
$$

Based on the fit, oxygen appears to have an effect on both the linear and exponential coefficients. This model is empirical and does not predict effective oxygen concentration as a function of temperaturedependent changes in oxygen solubility and diffusion. Increased oxygen may allow some additional growth acceleration, but the acceleration of growth rate appears to be leveling off, asymptotically approaching a maximum. At lower oxygen levels, the prevalence of arrest is expected to overtake the observed response curve.

\section{Discussion}

We tracked embryogenesis at different oxygen concentrations to determine its effect on development, performing these experiments in conjunction with precise temperature control. We found that developmental rate is highly dependent on oxygen and exhibits a complex relationship with temperature. Embryos are not as robust to oxygen changes and have much less of a dynamic response than is seen with temperature. We observed significant differences in oxygen responsiveness across tissues and morphological events. These changes can be aggravated by temperature (long known to interact with oxygen consumption ${ }^{24,34}$ ) to reveal situations in which embryogenesis loses its uniform thermal scaling.
The prevalence and timing of developmental failure depend strongly on oxygen. Under hypoxia, failure is largely concentrated in mid-embryogenesis at germ band retraction. Commonly the germ band fails to fully retract to expose the amnioserosa. It is possible that this stage either requires more oxygen or its complexity makes it prone to failure. A checkpoint at this stage that hypoxic embryos fail to pass may explain this phenotype. Rapid hypoxic arrests are not frequently observed under our conditions. Oxygen concentrations of $10 \%$ and $14 \%$ may fail to trigger complete hypoxic arrest in a subset of embryos yet serve to slow development enough to cause problems. Increasing oxygen levels would likely restart development, but the manner in which it restarts would depend on the stage of arrest, duration of hypoxia, and revived oxygen levels. Thermal tolerance has been previously linked to oxygen concentration ${ }^{34-36}$. Likewise, we see increased hypoxic mortality with increased temperature.

Hypoxia's mid to late embryogenesis failure contrasts with high heat and high oxygen, where failure occurs during early development, during either the syncytium or early gastrulation. Under conditions with high oxygen tension, death frequently resembles, at least qualitatively, high temperature normoxia death. Failure during syncytial development commonly involves mass migration of nuclei throughout the embryo, making it difficult to distinguish the point of failure between pre-gastrulation death resulting in nuclei migration and premature gastrulation that causes death.

The syncytium responds differently to oxygen levels than other embryonic stages. Perfect scaling collapses in the syncytium at high temperatures ${ }^{1}$, so it is not surprisingly that a difference is seen with the oxygen response as well. Interestingly, while syncytial development is less responsive to changes in oxygen than other stages across the range we tested, it is more responsive to excess heat than other stages. The difference may be aggravated by the lack of transcriptional responses available at that stage and the limited repertoire of maternally deposited genes and mRNAs. This may lead to the syncytium lacking high heat mitigations and prophylactic hypoxic responses. This implies that transcriptionally active embryos deliberately slow development either under high heat when kinetics are accelerating or under hypoxia to conserve energy.

The developmental rate response to oxygen is more subtle, yet causes more problems, across the range we tested than is seen with a moderate change in temperature. We measured ambient oxygen, meaning the exact oxygen concentration in the embryo microenvironment may differ. Across a $10^{\circ} \mathrm{C}$ differential, developmental time doubles with minimal change in viability. This is virtually invariant, regardless of oxygen concentrations. However, across a 19\% change in oxygen concentration, development time experiences an absolute, rather than proportional, change of sixteen to eighteen hours. Changes in oxygen thus provide a proportionally smaller change in developmental time with enormous consequences for viability. While changes in temperature follow the Arrhenius equation, changes with oxygen appear to follow Monod's equation. Rather than a logarithmic curve, developmental time is inversely proportional to oxygen concentration. This comparatively shallow oxygen response undermines the hypothesis, which had previously been refuted for thermal limits ${ }^{37,38}$, that oxygen availability explains 

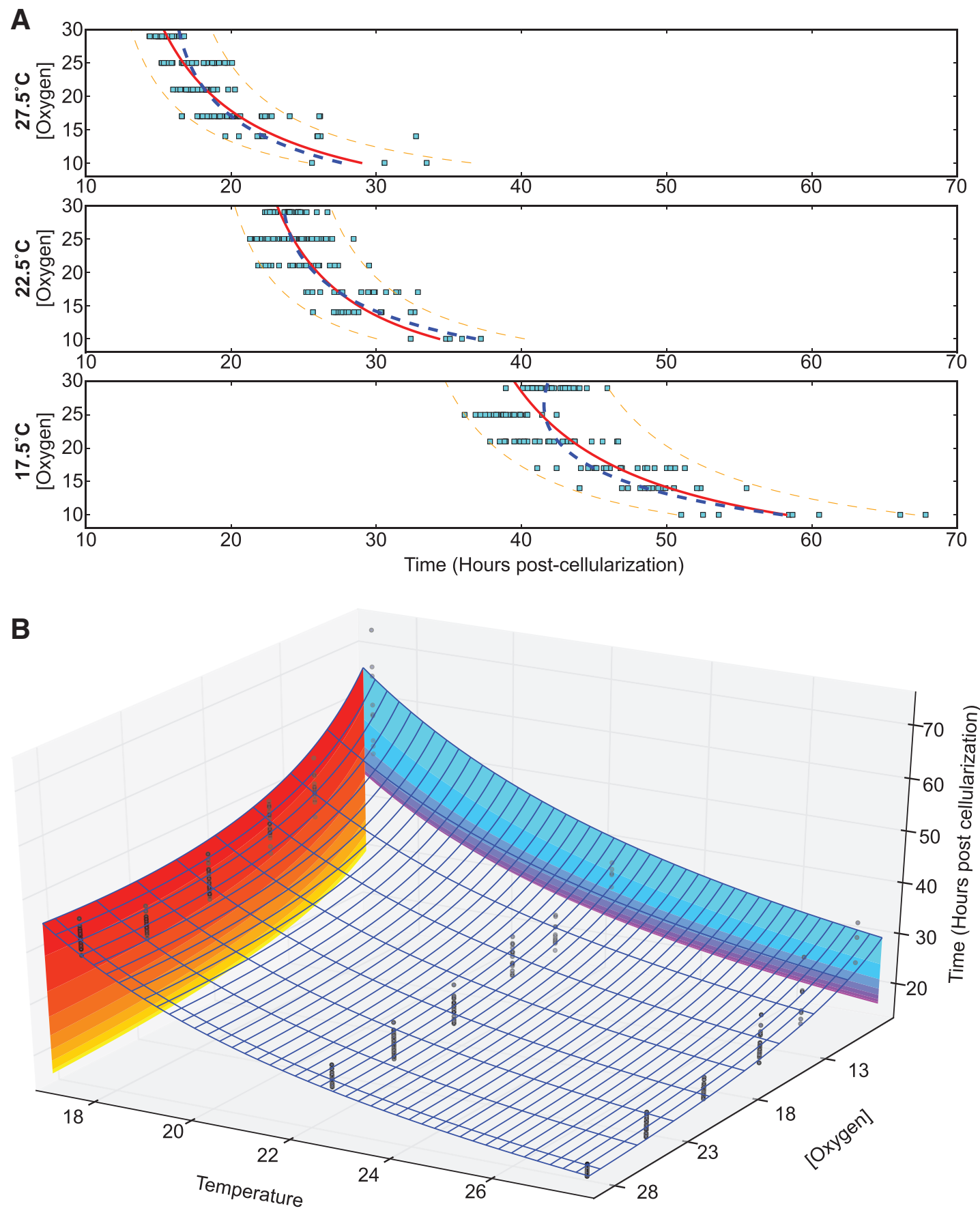

Figure 4. Oxygen and temperature affect developmental time cooperatively. (A) Fitting at different temperatures $\left(27.5^{\circ} \mathrm{C}, 22.5^{\circ} \mathrm{C}, 17.5^{\circ} \mathrm{C}\right.$ ) The shift is very temperature-dependent. The solid red line represents a fit at each particular temperature, with $90 \%$ confidence of reproduction marked with the dashed orange line. The blue dashed line represents the fit across all temperatures, which departs from the individual temperature fits. (B) Total developmental time is affected by both temperature and oxygen levels. Each point represents an individual embryo at a given temperature and oxygen level. Color contours help visualize the transitions of increased heat (yellow to red contour) and increased oxygen (purple to blue contour). 
temperature-dependent changes. Changes in temperature will affect oxygen diffusion in the embryo, with a $10^{\circ} \mathrm{C}$ change shifting the effective oxygen concentration by $\sim 4 \%$. However, the difference in developmental time between $21 \%$ and $17 \%$ oxygen at $27.5^{\circ} \mathrm{C}$ is dwarfed by the dramatically larger difference between $27.5^{\circ} \mathrm{C}$ and $17.5^{\circ} \mathrm{C}$ at $21 \%$. Therefore, basic energy metabolism is not solely responsible for the changes in developmental rates seen across temperature. Our results show that the embryo's developmental program is robust to small changes in oxygen. This suggests some leeway in respiration efficiency; nevertheless, there is a notable biological response.

\section{Data availability}

Figshare: Raw data for Kuntz and Eisen, 2015 'Oxygen changes drive non-uniform scaling in Drosophila melanogaster embryogenesis'. 10.6084/m9.figshare. $1582639^{39}$

Figshare: Oxygen imaging. 10.6084/m9.figshare.1572474 ${ }^{40}$

Author contributions

Conceived and designed the experiments: SGK MBE. Performed the experiments: SGK. Analyzed the data: SGK. Algorithms used in analysis: SGK. Contributed reagents/materials/analysis tools: SGK MBE. Wrote the paper: SGK MBE.

\section{Competing interests}

MBE is on the International Advisory Board for F1000.

\section{Grant information}

This work was supported by a Howard Hughes Medical Institute investigator award to MBE and by NIH grant HG002779 to MBE. SGK was supported by the National Institutes of Health under Ruth L. Kirschstein National Research Service Award (F32-FGM101960A) from the National Institute of General Medical Sciences.

I confirm that the funders had no role in study design, data collection and analysis, decision to publish, or preparation of the manuscript.

Acknowledgements

Stocks obtained from the Bloomington Drosophila Stock Center (NIH P40OD018537) were used in this study. We thank BCK and EDKK for their support.

\section{Supplementary material}

Table S1. Point of Failure.

\begin{tabular}{|c|c|c|c|c|c|c|c|c|c|c|c|c|}
\hline \multirow{5}{*}{$\begin{array}{c}\begin{array}{c}\text { Oxygen } \\
\text { Concentration }\end{array} \\
\\
29 \%\end{array}$} & \multirow{2}{*}{$\begin{array}{c}\text { Temperature } \\
32.5^{\circ} \mathrm{C}\end{array}$} & \multicolumn{2}{|c|}{$\begin{array}{c}\text { Syncytial or } \\
\text { Gastrulation } \\
\text { Death }\end{array}$} & \multicolumn{2}{|c|}{$\begin{array}{l}\text { Death before } \\
\text { Heart-shaped } \\
\text { Midgut }\end{array}$} & \multicolumn{2}{|c|}{$\begin{array}{l}\text { Death before } \\
\text { Trachea } \\
\text { Formation }\end{array}$} & \multicolumn{2}{|c|}{$\begin{array}{l}\text { Failure to } \\
\text { Hatch }\end{array}$} & \multicolumn{2}{|c|}{$\begin{array}{l}\text { Successful } \\
\text { Hatch }\end{array}$} & \multirow{2}{*}{\begin{tabular}{|c|} 
Total \\
30
\end{tabular}} \\
\hline & & 26 & $87 \%$ & 4 & $13 \%$ & - & - & - & - & - & - & \\
\hline & $27.5^{\circ} \mathrm{C}$ & - & - & 1 & $2 \%$ & 1 & $2 \%$ & 8 & $18 \%$ & 35 & $78 \%$ & 45 \\
\hline & $22.5^{\circ} \mathrm{C}$ & 13 & $28 \%$ & - & - & - & - & 2 & $4 \%$ & 31 & $67 \%$ & 46 \\
\hline & $17.5^{\circ} \mathrm{C}$ & 6 & $11 \%$ & - & - & - & - & 4 & $8 \%$ & 43 & $81 \%$ & 53 \\
\hline \multirow{3}{*}{$25 \%$} & $27.5^{\circ} \mathrm{C}$ & 3 & $8 \%$ & 1 & $3 \%$ & 3 & $8 \%$ & 2 & $6 \%$ & 27 & $75 \%$ & 36 \\
\hline & $22.5^{\circ} \mathrm{C}$ & 2 & $4 \%$ & 2 & $4 \%$ & - & - & - & - & 46 & $92 \%$ & 50 \\
\hline & $17.5^{\circ} \mathrm{C}$ & 1 & $4 \%$ & - & - & - & - & - & - & 22 & $96 \%$ & 23 \\
\hline \multirow{3}{*}{$21 \%$} & $27.5^{\circ} \mathrm{C}$ & 3 & $6 \%$ & - & - & 4 & $9 \%$ & 14 & $30 \%$ & 26 & $55 \%$ & 47 \\
\hline & $22.5^{\circ} \mathrm{C}$ & 2 & $6 \%$ & - & - & 1 & $3 \%$ & 4 & $12 \%$ & 27 & $79 \%$ & 34 \\
\hline & $17.5^{\circ} \mathrm{C}$ & 8 & $17 \%$ & 1 & $2 \%$ & 4 & $9 \%$ & 8 & $17 \%$ & 26 & $55 \%$ & 47 \\
\hline \multirow{4}{*}{$17 \%$} & $30.0^{\circ} \mathrm{C}$ & 40 & $98 \%$ & 1 & $2 \%$ & - & - & - & - & - & - & 41 \\
\hline & $27.5^{\circ} \mathrm{C}$ & 1 & $2 \%$ & - & - & 13 & $25 \%$ & 26 & $50 \%$ & 12 & $23 \%$ & 52 \\
\hline & $22.5^{\circ} \mathrm{C}$ & 6 & $13 \%$ & 2 & $4 \%$ & 12 & $25 \%$ & 10 & $21 \%$ & 18 & $38 \%$ & 48 \\
\hline & $17.5^{\circ} \mathrm{C}$ & 3 & $8 \%$ & 2 & $5 \%$ & 2 & $5 \%$ & 11 & $28 \%$ & 22 & $55 \%$ & 40 \\
\hline \multirow{3}{*}{$14 \%$} & $27.5^{\circ} \mathrm{C}$ & 19 & $38 \%$ & 17 & $34 \%$ & 6 & $12 \%$ & 8 & $16 \%$ & - & - & 50 \\
\hline & $22.5^{\circ} \mathrm{C}$ & 2 & $4 \%$ & 2 & $4 \%$ & 9 & $18 \%$ & 25 & $49 \%$ & 13 & $25 \%$ & 51 \\
\hline & $17.5^{\circ} \mathrm{C}$ & 7 & $12 \%$ & 3 & $5 \%$ & 21 & $36 \%$ & 13 & $22 \%$ & 15 & $25 \%$ & 59 \\
\hline \multirow{3}{*}{$10 \%$} & $27.5^{\circ} \mathrm{C}$ & 11 & $24 \%$ & 14 & $31 \%$ & 17 & $38 \%$ & 3 & $7 \%$ & - & - & 45 \\
\hline & $22.5^{\circ} \mathrm{C}$ & 3 & $8 \%$ & 14 & $36 \%$ & 16 & $41 \%$ & 6 & $15 \%$ & - & - & 39 \\
\hline & $17.5^{\circ} \mathrm{C}$ & 17 & $29 \%$ & 17 & $29 \%$ & 11 & $19 \%$ & 14 & $24 \%$ & - & - & 59 \\
\hline
\end{tabular}




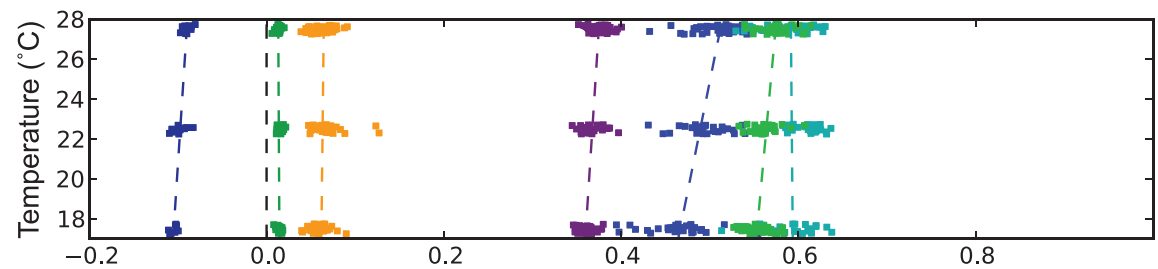

$25 \% \mathrm{O}_{2}$
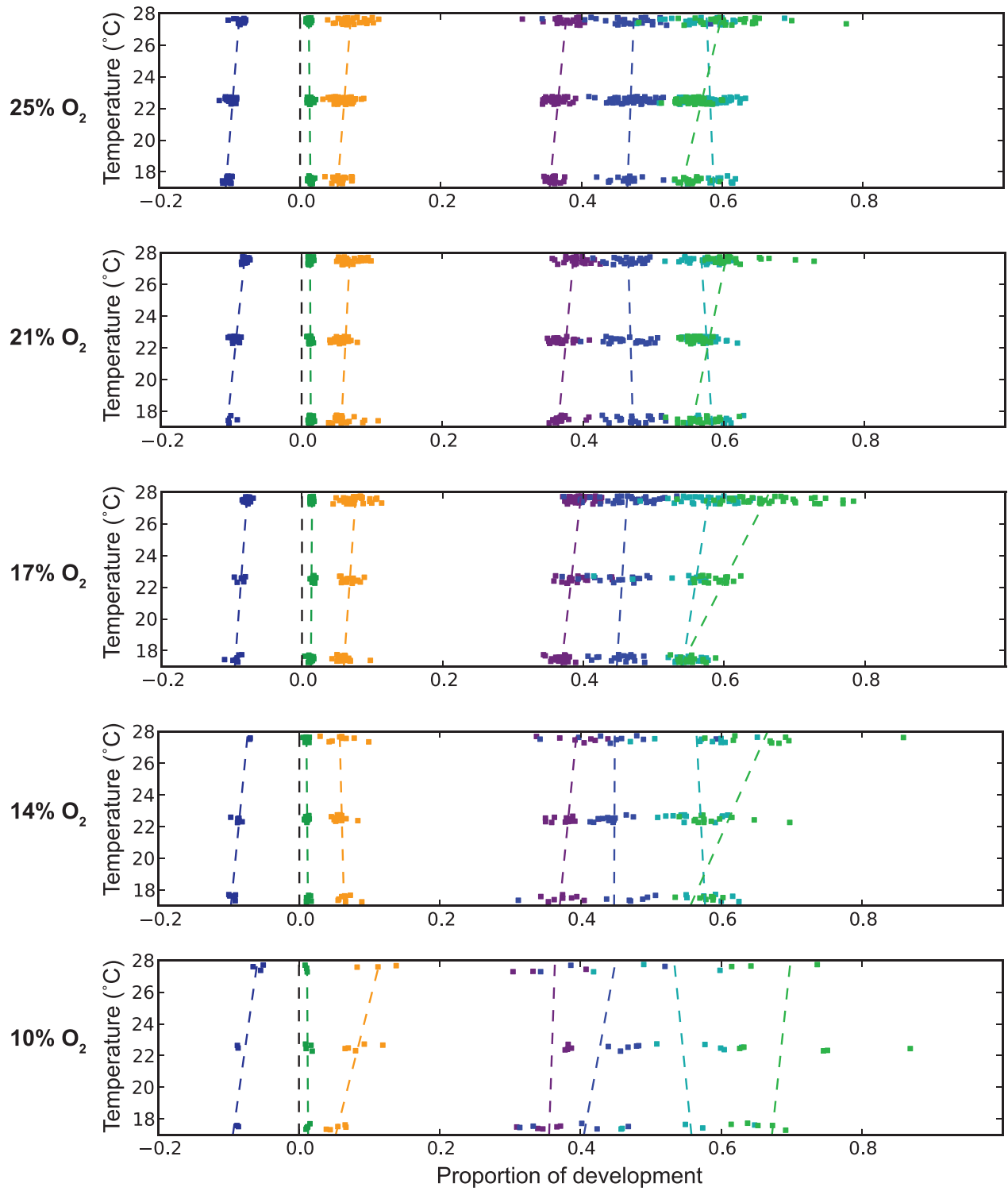

Figure S1. Changes in stages react differently as temperature changes. As oxygen concentrations decrease, gut-development is proportionally delayed, as can be seen with the timing of the heart-shaped midgut shifting later in development. Proportional changes in development are more severe at higher temperatures. At very low oxygen concentrations (10\% oxygen), development becomes highly irregular. In many animals, development ceases during germ band retraction at very low oxygen concentrations. Development is normalized here between the end of cellularization and the filling of the trachea. 

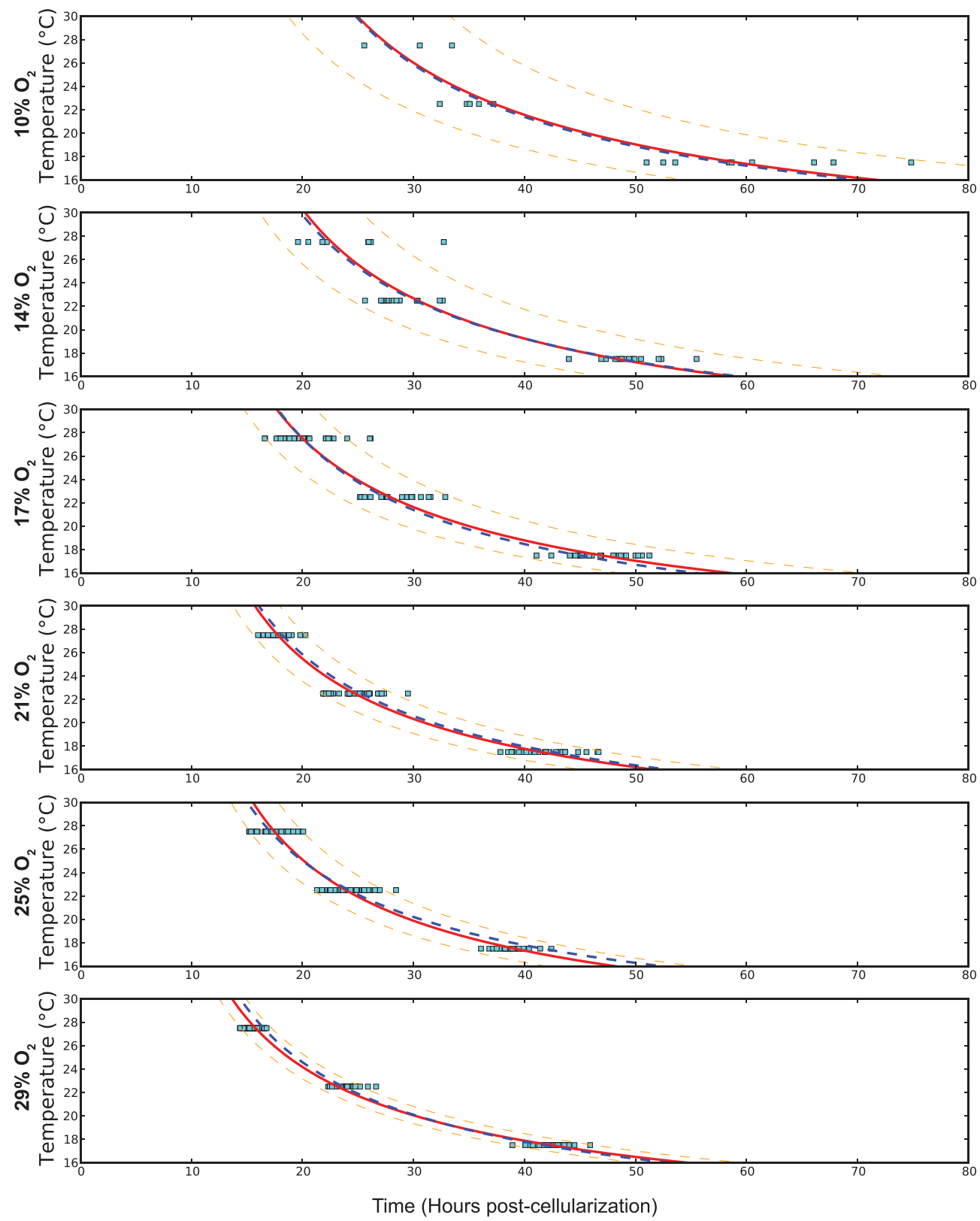

Figure S2. Curve fitting for each oxygen concentration as temperature changes. Curve fitting at each oxygen concentration is shown with the red line, with the $90 \%$ confidence interval delineated by the orange dashed line. The overall curve fitting is identified with the blue dashed line. Differences between different oxygen concentrations are much smaller than the range covered by temperature changes. The change in developmental time from high to low temperatures remains proportional across oxygen concentrations. 
1. Kuntz SG, Eisen MB: Drosophila embryogenesis scales uniformly across temperature in developmentally diverse species. PLOS Genet. 2014; 10(4): e1004293

PubMed Abstract | Publisher Full Text | Free Full Text

2. Cruz SR, Romanoff AL: Effect of oxygen concentration on the development of the chick embryo. Physiol Zool. 1944; 17(2): 184-187. Reference Source

3. Simon MC, Keith B: The role of oxygen availability in embryonic development and stem cell function. Nat Rev Mol Cell Biol. 2008; 9(4): 285-296. PubMed Abstract | Publisher Full Text | Free Full Text

4. Reiling JH, Hafen E: The hypoxia-induced paralogs Scylla and Charybdis inhibit growth by down-regulating S6K activity upstream of TSC in Drosophila. Genes Dev. 2004; 18(23): 2879-2892. PubMed Abstract | Publisher Full Text | Free Full Text

5. Hidalgo M, Le Bouffant R, Bello V, et al.: The translational repressor 4E-BP mediates hypoxia-induced defects in myotome cells. J Cell Sci. 2012; 125(Pt 17): 3989-4000.

PubMed Abstract | Publisher Full Text

6. Bianchini K, Wright PA: Hypoxia delays hematopoiesis: retention of embryonic hemoglobin and erythrocytes in larval rainbow trout, Oncorhynchus mykiss, during chronic hypoxia exposure. J Exp Biol. 2013; 216(Pt 23): 4415-4425. PubMed Abstract | Publisher Full Text

7. Lee SW, Yang J, Kim SY, et al:: MicroRNA-26a induced by hypoxia targets HDAC6 in myogenic differentiation of embryonic stem cells. Nucleic Acids Res. 2015; 43(4): 2057-2073.

PubMed Abstract | Publisher Full Text | Free Full Text

8. Majmundar AJ, Lee DS, Skuli N, et al:: HIF modulation of Wnt signaling regulates skeletal myogenesis in vivo. Development. 2015; 142(14): 2405-2412. PubMed Abstract | Publisher Full Text | Free Full Text

9. Merceron C, Mangiavini L, Robling A, et al.: Loss of HIF-1 $\alpha$ in the notochord results in cell death and complete disappearance of the nucleus pulposus. PLoS One. 2014; 9(10): e110768.

PubMed Abstract | Publisher Full Text | Free Full Text

10. Lin TY, Chou CF, Chung HY, et al:: Hypoxia-inducible factor 2 alpha is essentia for hepatic outgrowth and functions via the regulation of leg1 transcription in the zebrafish embryo. PLOS One. 2014; 9(7): e101980. PubMed Abstract | Publisher Full Text | Free Full Text

11. Douglas RM, Xu T, Haddad GG: Cell cycle progression and cell division are sensitive to hypoxia in Drosophila melanogaster embryos. Am J Physiol Regul Integr Comp Physiol. 2001; 280(5): R1555-63. PubMed Abstract

12. Foe VE, Alberts BM: Reversible chromosome condensation induced in Drosophila embryos by anoxia: visualization of interphase nuclear organization. J Cell Biol. 1985; 100(5): 1623-1636. PubMed Abstract | Publisher Full Text | Free Full Text

13. DiGregorio PJ, Ubersax JA, O'Farrell PH: Hypoxia and nitric oxide induce rapid, reversible cell cycle arrest of the Drosophila syncytial divisions. $J$ Biol Chem. 2001; 276(3): 1930-1937. PubMed Abstract | Publisher Full Text | Free Full Text

14. Heinrich EC, Farzin M, Klok CJ, et al:: The effect of developmental stage on the sensitivity of cell and body size to hypoxia in Drosophila melanogaster. $J$ Exp Biol. 2011; 214(Pt 9): 1419-1427. PubMed Abstract | Publisher Full Text | Free Full Text

15. Harrison JF, Shingleton AW, Callier V: Stunted by developing in hypoxia: Linking comparative and model organism studies. Physiol Biochem Zool. 2015; 88(5): $455-470$.

Publisher Full Text

16. Peck LS, Maddrell SH: Limitation of size by hypoxia in the fruit fly Drosophila melanogaster. J Exp Zool A Comp Exp Biol. 2005; 303(11): 968-975. PubMed Abstract | Publisher Full Text

17. Wingrove JA, O'Farrell PH: Nitric oxide contributes to behavioral, cellular, and developmental responses to low oxygen in Drosophila. Cell. 1999; 98(1): 105-114.

PubMed Abstract | Publisher Full Text | Free Full Text

18. Teodoro RO, O'Farrell $\mathrm{PH}$ : Nitric oxide-induced suspended animation promotes survival during hypoxia. EMBO J. 2003; 22(3): 580-587. PubMed Abstract | Publisher Full Text | Free Full Text

19. Arquier N, Vigne $P$, Duplan $E$, et al:: Analysis of the hypoxia-sensing pathway in Drosophila melanogaster. Biochem J. 2006; 393(Pt 2): 471-80. PubMed Abstract | Publisher Full Text | Free Full Text

20. Williams CM, Beecher HK: Sensitivity of Drosophila to poisoning by oxygen.
Am J Physiol 1944: 140: 566-573.

Reference Source

21. Clark AM, Herr EB Jr: The sensitivity of developing Habrobracon to oxygen. Biol Bull. 1954; 107(3): 329-334.

Publisher Full Text

22. Walker DW, Benzer S: Mitochondrial "swirls" induced by oxygen stress and in the Drosophila mutant hyperswirl. Proc Natl Acad Sci U S A. 2004; 101(28): 10290-10295.

PubMed Abstract | Publisher Full Text | Free Full Text

23. O'Farrell PH: Conserved responses to oxygen deprivation. J Clin Invest. 2001; 107(6): 671-674.

PubMed Abstract | Publisher Full Text | Free Full Text

24. Rogers $E$ : The effect of temperature on the oxygen consumption of an insect, Melano-plus differentialis. Physiol Zool. 1929; 2(2): 275-283.

Reference Source

25. Garside ET: Some effects of oxygen in relation to temperature on the development of lake trout embryos. Can J Zool. 1959; 37(5): 689-698. Publisher Full Text

26. Lavista-Llanos S, Centanin L, Irisarri M, et al.: Control of the hypoxic response in Drosophila melanogaster by the basic helix-loop-helix PAS protein similar. Mol Cell Biol. 2002; 22(19): 6842-6853.

PubMed Abstract | Publisher Full Text | Free Full Text

27. Irisarri M, Lavista-Llanos S, Romero NM, et al.: Central role of the oxygendependent degradation domain of Drosophila HIFalpha/Sima in oxygendependent nuclear export. Mol Biol Cell. 2009; 20(17): 3878-3887. PubMed Abstract | Publisher Full Text | Free Full Text

28. Dekanty A, Lavista-Llanos S, Irisarri M, et al:: The insulin-PI3K/TOR pathway induces a HIF-dependent transcriptional response in Drosophila by promoting nuclear localization of HIF-alpha/Sima. J Cell Sci. 2005; 118(Pt 23): 5431-5441. PubMed Abstract | Publisher Full Text

29. Van Voorhies WA: Metabolic function in Drosophila melanogaster in response to hypoxia and pure oxygen. J Exp Biol. 2009; 212(19): 3132-3141. PubMed Abstract | Publisher Full Text | Free Full Text

30. Clare MR: A study of oxygen metabolism in Drosophila melanogaster. Biol Bull. 1925; 49(6): 440-460. Publisher Full Text

31. Tennessen JM, Thummel CS: Coordinating growth and maturation - insights from Drosophila. Curr Biol. 2011; 21(18): R750-R757. PubMed Abstract | Publisher Full Text | Free Full Tex

32. De Renzis $S$, Elemento $O$, Tavazoie $S$, et al: Unmasking activation of the zygotic genome using chromosomal deletions in the Drosophila embryo. PLOS BiOl. 2007; 5(5): e117. PubMed Abstract | Publisher Full Text | Free Full Text

33. Technau GM: Lineage analysis of transplanted individual cells in embryos of Drosophila melanogaster. I. The method. Roux's Arch Dev Biol. 1986; 195(6): 389-398.

Publisher Full Text

34. Frazier MR, Woods HA, Harrison JF: Interactive effects of rearing temperature and oxygen on the development of Drosophila melanogaster. Physiol Biochem Zool. 2001; 74(5): 641-650.

PubMed Abstract | Publisher Full Text

35. Bjelde BE, Miller NA, Stillman JH, et al:: The role of oxygen in determining upper thermal limits in Lottia digitalis under air exposure and submersion.

Physiol Biochem Zool. 2015; 88(5): 483-493. Publisher Full Text

36. Liang L, Sun BJ, Ma L, et al.: Oxygen-dependent heat tolerance and developmental plasticity in turtle embryos. J Comp Physiol B. 2015; 185(2): 257-263.

PubMed Abstract | Publisher Full Text

37. McCue MD, De Los Santos R: Upper thermal limits of insects are not the result of insufficient oxygen delivery. Physiol Biochem Zool. 2013; 86(2): 257-265. PubMed Abstract | Publisher Full Text

38. Mölich AB, Förster TD, Lighton JR: Hyperthermic overdrive: oxygen delivery does not limit thermal tolerance in Drosophila melanogaster. J Insect Sci. 2012 12: 109.

PubMed Abstract | Publisher Full Text | Free Full Text

39. Kuntz S, Eisen M: Raw data for Kuntz and Eisen, 2015 'Oxygen changes drive non-uniform scaling in Drosophila melanogaster embryogenesis'. Figshare. 2015. Data Source

40. Kuntz S: Oxygen imaging. Figshare. 2015.

Data Source 


\section{Open Peer Review}

\section{Current Peer Review Status:}

\section{Version 1}

Reviewer Report 23 November 2015

https://doi.org/10.5256/f1000research.7779.r11301

(C) 2015 Wappner P. This is an open access peer review report distributed under the terms of the Creative Commons Attribution License, which permits unrestricted use, distribution, and reproduction in any medium, provided the original work is properly cited.

\section{Pablo Wappner \\ Leloir Institute Foundation, Buenos Aires, Argentina}

Kuntz and Eisen have analysed the effect that variations of oxygen concentrations and temperature exert on Drosophila embryonic development. A previous study from the same group had shown that temperature variations affect embryogenesis preserving the order and relative duration of a list of morphological events during this developmental process. The question addressed in this work is as whether variations of oxygen levels also preserve the order and relative duration of events during embryogenesis. They have designed and built a special device to monitor embryogenesis while controlling oxygen levels and temperature simultaneously. The work is technically sound and the results are truly unexpected: The different morphological events of the embryogenesis are not affected by oxygen levels to a similar extent, but rather, each morphological event responds to such variations in an unequal manner. Strikingly, the order in which some of the morphological events occur is altered when oxygen levels are modified. These effects are modulated by the temperature, so that the order and relative duration of each of the events of the embryogenesis is independently modulated by oxygen and temperature simultaneously. The approach and the whole concept is highly original and adds a new dimension to our understanding of metazoan development that paves the road for further studies aimed to the definition of the molecular and genetic mechanisms that underlie this phenomenon.

Competing Interests: No competing interests were disclosed.

\section{I confirm that I have read this submission and believe that I have an appropriate level of expertise to confirm that it is of an acceptable scientific standard.}

Reviewer Report 16 November 2015

https://doi.org/10.5256/f1000research.7779.r11218 
(C) 2015 DePace A. This is an open access peer review report distributed under the terms of the Creative Commons Attribution License, which permits unrestricted use, distribution, and reproduction in any medium, provided the original work is properly cited.

\section{Angela H. DePace}

Department of Systems Biology, Harvard Medical School, Boston, MA, USA

This study assesses the effect of oxygen level and temperature on developmental timing in Drosophila embryos. The methods are adequately described to interpret the experiments. Oxygen and temperature are controlled externally in a custom built apparatus. Developmental timing is assessed by time lapse imaging under bright field; developmental milestones were manually annotated from this data. The statistical analysis used to compare across conditions is adequately described. This experimental set up does not make any internal measurements of oxygen level or temperature, which may be of interest for future studies, but this is a substantial technical undertaking.

The conclusions are primarily descriptive-the relative duration and timing of developmental stages varies in a non-uniform way with oxygen level and the effect depends on temperature. This result contrasts with the effect of varying temperature alone, where developmental stages maintain precise relative timing despite variation of the overall time of development, as described in a previous study by the same authors. The authors also pinpoint which stages and tissues are most sensitive to changes in oxygen level. These phenomenological conclusions will be useful for future studies.

There are also some secondary interpretations based on their phenomenological observations.

First, because the blastoderm stage is more responsive to changes in temperature than other stages, but less responsive to changes in oxygen, the authors speculate that this is because blastoderm embryos have a limited ability to mitigate heat stress via transcription of new genes or translation of existing mRNA. Reciprocally, they state that "transcriptionally active embryos" (I read this to mean non-blastoderm embryos) "deliberately slow development either under high heat when kinetics are accelerating or under hypoxia to conserve energy." In my opinion, this interpretation doesn't immediately follow from the previous observation about the heat and oxygen sensitivity of blastoderm embryos. It is also not clear what the authors mean by "deliberately"; perhaps they mean that the embryos have pathways dedicated to a regulated response to these conditions, rather than the effect arising passively from global biochemical parameters.

Second, the authors state that the thermal response is not due to changes in oxygen delivery as the two responses have distinct dynamics and phenotypic outcomes. This generalizes previous results about oxygen availability under extreme temperatures, as pointed out by the authors. In my view, this interpretation is sound.

In my opinion, one of the most interesting directions for this line of research is how variation in temperature and oxygen level are sensed and how responses are executed. In the previous paper, the authors stated that they expected non-uniform scaling in response to temperature, because chemical reactions are known to exhibit different temperature sensitivity. Under this line 
of thinking, pathways specific to distinct developmental stages would respond differently to temperature, resulting in heterochrony. Instead, they do find uniform scaling of developmental timing in response to temperature. In this work, specific pathways are known to have differential sensitivity to oxygen (as described in the introduction), and indeed they observe heterochrony. What underlies this difference? Are developmental pathways not differentially sensitive to temperature (or stated reciprocally, do they all respond to temperature the same way)? Or are different molecular or pathway level effects of temperature buffered by other systems? Both of these are interesting possibilities. Deciphering whether uniform temperature sensitivity and/or buffering are under selection will also be exciting.

Competing Interests: No competing interests were disclosed.

\section{I confirm that I have read this submission and believe that I have an appropriate level of expertise to confirm that it is of an acceptable scientific standard.}

Reviewer Report 10 November 2015

https://doi.org/10.5256/f1000research.7779.r10904

(c) 2015 Lavista Llanos S. This is an open access peer review report distributed under the terms of the Creative Commons Attribution License, which permits unrestricted use, distribution, and reproduction in any medium, provided the original work is properly cited.

\section{Sofia Lavista Llanos}

Department of Evolutionary Neuroethology, Max Planck Institute for Chemical Ecology, Jena, Germany

\section{Motivation:}

Authors have previously shown for various Drosophila species, that the relative timing of events within embryogenesis is temperature indifferent (ref 1 in manuscript). To test if this uniform scaling with varying temperature is an intrinsic property of developing embryos, or rather a specific response to thermal fluctuations, authors soughed a temperature-independent manner to manipulate the embryogenesis development rate.

\section{Proposed study:}

Authors studied the development scale of embryos grown at different oxygen concentrations and its interaction with varying temperatures.

\section{Main result found:}

In contrast to the uniform scaling of development with temperature variation, authors found heterochrony of the developmental events with changes in oxygen levels. There was an interaction between temperature and oxygen.

\section{Conclusions:}

These data reveal that the uniform scaling seen with changes in temperature is not a trivial consequence of adjusting developmental rate. 
Authors inaccurately raise conclusions on the behaviour of developing embryos with fluctuating temperature (referred as to the previous study), based on experiments performed with varying oxygen in the present study.

Instead, the data presented in this study supports the hypothesis that a uniform scaling of development is not an intrinsic property of developing embryos. Rather, embryos adjust their developmental program in different ways depending on variable ambient conditions.

\section{Relevance of the study:}

Considering the importance of studies on tissue and cellular responses to hypoxia, for human health (i.e.: tumour growth and cardiovascular disease, among others) this study could potentially become of great impact.

\section{Control aspects that should be addressed:}

1. Authors assume that $\mathrm{O}_{2}$ is delivered uniformly through the embryo, as most probably temperature does. Are the results here obtained simply a consequence of a differential diffusion of $\mathrm{O}_{2}$ through the embryonic tissues?

2. Does temperature affect $\mathrm{O}_{2}$ diffusion, explaining the interaction between both variables here shown?

3. Is there an effect of nitrogen changing concentration in the hypoxia treatments?

\section{Derived biological questions \& suggestions:}

1. Is the oxygen dependency of developmental rate conserved in the different Drosophila species?

2. The non-uniform scaling of development in hypoxia might indicate that oxygen plays a signalling role during the developmental process (see Jarecki et al., 1999).

3. Might mild physiological hypoxia in embryonic deep tissues explain the differential reluctance to oxygen deprivation of different tissues?

4. Is the embryonic developmental program a coordinated hierarchical chain of events, being the chronological appearance of each one dependent on the occurrence of the previous event? Or, rather, is the embryonic developmental program a sum of independent events each following an autonomous synchrony and/or independent scaling that adjusts to the ambient conditions? Or a combination of both? These aspects could actually be addressed in the manuscript based on the results obtained with varying temperature (previous study) and varying oxygen (results shown here).

5. Authors could put their results into an ecological context, comparing species with different habitats and ovipositon sites.

6. These studies were done on de-chorionated embryos. Authors could address the fact that chorion might serve as a physiological barrier to fluctuating oxygen concentrations, which would prevent desynchronising the embryonic development with varying ambient conditions.

\section{Proposed experiments:}

1. To reinforce the evidence of the role of oxygen/hypoxia on the development scale, authors could use mutants of the oxygen cellular sensing machinery (i.e.: Hph (CG31543), sima (CG7951); see Centanin et al., 2005) in time-lapse imaging experiments. Such experiments could serve to rule out a mere physic-chemical effect of hypoxia on the embryonic development scale and at the same time test if oxygen has an active signalling role during embryogenesis.

2. Authors could follow with fluorescent markers the dividing cells (e.g.: bromouridine) and or 
apoptotic cells (e.g.: TUNEL) during development at varying oxygen levels to get an insight on the cellular/molecular mechanisms sustaining the adjustment of the development to varying oxygen or temperature fluctuations.

3. Authors could try to address the embryonic internal oxygen concentrations by indirect labelling of populations of synchronized embryos (30 min egg-laying) fixed after the relevant oxygen/temperature treatments (e.g.: lac-Z/GFP staining using hypoxia reporter genes, NADPH diaphorase staining).

4. To test if the presence of chorion affects the response to varying oxygen, authors could repeat the experiments with synchronized chorioned eggs (30 min egg-laying) \& immediately dechorionated + fixed after treatment. This would test if indeed the ambient variation in oxygen affects development in nature.

5. Having overcome the challenge of obtaining developmental staged-matched samples for different species in their previous study (ref 1 in manuscript), authors could include different species to complement this study.

\section{Minor comments:}

1. Introduction paragraph-5 line-6: simalar should read 'similar'.

2. Methods: Egg-lays were performed in medium cages on $10 \mathrm{~cm}$ molasses plates for 1.5 hours at the temperature at which the lines were maintained after pre-clearing. This phrase is not clear. Were adult flies maintained at the same temperature as eggs? Does this affect the stage at which eggs are laid? With 1.5 hours collection eggs have an error of \pm 45 minutes, which at the beginning of embryogenesis might have huge effects on development.

3. How was the proportion of development calculated? Data quantification methods should be clearly detailed in methods section.

4. Figure 1: $Y$ axis is not in scale. Authors should also indicate in the figure legend the number of eggs $(n)$ for each experiment.

5. Results paragraph-3 line-5: Syncytial development, as measured by the time between the appearance of the pole bud and the end of cellularization, takes proportionally less time as oxygen concentrations decrease, indicating that this stage is not slowed as much by decreasing oxygen.

6. The event 'end of cellularization' is not shown on figure $1 \mathrm{C}$ legend.

7. Authors might want to re-phrase the passive voice in 'indicating that this stage is not slowed as much by decreasing oxygen' for ' indicating that decreasing oxygen does not slow this stage'.

8. I don't see the dependence of one argument with the other. Authors might want to rephrase the entire argument.

9. Results paragraph-3: The events mentioned in the text do not correspond to those shown in the figure legend. Authors might want to make it easier for the reader to follow their descriptions by choosing a uniform way of representing the data and referring to it in the text.

10. Figure 2: Legend reference does not correspond to the events described in the figure legend, making difficult for the reader to follow the arguments.

11. Table S1: legend missing; it might aid clarification to provide a legend to this table.

12. Figure S1: Title is not clear: Changes in stages react differently as temperature changes. What do they react to?

13. Figure S1: No reference legend is provided!

14. Discussion pagraph-2 line-6: A checkpoint at this stage that hypoxic embryos fail to pass may 
explain this phenotype. Phrase not clear.

15. Discussion: pagraph-5 line-3: Authors might suggest experiments to grasp this aspect.

16. Discussion: final conclusion does not correspond to the aim stated at the beginning of the manuscript.

Final comment: This study addresses an important topic relevant to biological and medical fields. Despite the fact that the conclusions raised are rather superficial, and regrettably inadequate to the objective aimed in the first place after major revision (!), this manuscript could make an important contribution to Drosophila embryogenesis and, more general, to homeostasis of animal development.

Competing Interests: No competing interests were disclosed.

I confirm that I have read this submission and believe that I have an appropriate level of expertise to confirm that it is of an acceptable scientific standard, however I have significant reservations, as outlined above.

The benefits of publishing with F1000Research:

- Your article is published within days, with no editorial bias

- You can publish traditional articles, null/negative results, case reports, data notes and more

- The peer review process is transparent and collaborative

- Your article is indexed in PubMed after passing peer review

- Dedicated customer support at every stage

For pre-submission enquiries, contact research@f1000.com

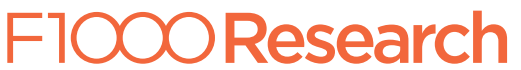

